\title{
Perspective Electrical Circuit Simulation with Virtual Reality
}

\author{
https://doi.org/10.3991/ijoe.v15i05.9653 \\ Sumitra Nuanmeesri $\left({ }^{\bowtie}\right)$,Lap Poomhiran \\ Suan Sunandha Rajabhat University, Bangkok, Thailand \\ sumitra.nuessru.ac.th
}

\begin{abstract}
Focusing on electrical circuits as the topic for a STEM project, this research aims to develop virtual reality media for student learning. Using virtual reality media to perform STEM electrical circuit activities, data was collected and analyzed. The virtual reality media was then evaluated by five experts who used the Index of Item-Objective Congruence (IOC) to assess its effectiveness, where the IOC for each criteria was 0.8 or higher. Moreover, after evaluating it with the Diffusion of Innovation Theory (DOI), the arithmetic mean of its effectiveness on the diffusion of innovation was 4.32 , with a 0.48 standard deviation. This demonstrates that the use of virtual reality media was a beneficial innovation at a high level. Afterwards, the developed virtual reality media was evaluated by a sample of 30 subjects in the areas of VR features, usability, learning experience, and VR measurement outcomes. The findings show that its arithmetic mean was 4.67 with a 0.47 standard deviation, meaning the developed virtual reality media was an effective for electrical circuit learning at the highest level. Furthermore, after evaluating its effectiveness in the area of information technology acceptance, it was found that, for these criteria, the arithmetic mean was 4.64 with a standard deviation of 0.48 . This indicates that the subjects generally accepted the use of virtual reality media for use in learning STEM activities at the highest level. It can be said that the development of the virtual reality media for learning STEM activities with a focus on electrical circuits enhances the learning process of the learners who confirmed such statements at the highest level, with an increase in subject understanding of the learning activity and self-satisfaction, while at the same time reducing the prejudice learners have towards the study of electrical circuit installation.
\end{abstract}

Keywords-Virtual Reality, VR, Electrical Circuits, Electronics Education, 3D Graphics, Simulation

\section{Introduction}

The study of electrical circuits is the basis of contemporary technology which requires a basic knowledge and understanding of electricity. This is a requirement in the electronic equipment and electronic devices assembly industries. During the production process, engineers in this field must apply their knowledge of electrical circuits, from design, through production, and then delivery. In general, electricity is intangi- 
ble. Learners must use their imagination and electronic laboratories to support their studies and develop their comprehension. While studying, the learners must be crucially careful as there are dangers associated with working with electrical components and appliances, some of which can be lethal. Electronic laboratories normally require expensive experimental instruments and other equipment, so it is important to maintain a high level of safety and spend huge budgets on the preparation of electrical circuit-intensive materials and equipment for learning. Poor educational institutions may make use of two-dimensional educational demonstrations or presentations to teach students the fundamentals of electrical circuitry. The pictures shown in textbooks, websites, social media, etc., tend to provide the learner with a degraded experience when compared to hands-on activities.

Virtual Reality (VR) is a technology that has been well-received, being successfully applied in the field of education. Also referred to as 'Virtual Reality Learning Environments' (VRLEs) [1], recent studies have demonstrated that virtual learning applications can provide the learning tools that support learning in a rapid and entertaining manner (Pan et al., 2006). By using virtual reality, students are able to learn in a near hands-on environment. This mode of learning is a tool that has become greatly appreciated by instructors and learners [19], [20]. Principally, virtual reality technology has three common features, being interactive, immersive, and imaginative. The immersive quality refers to how a user can directly engage in the three-dimensional scene via the presentation of a virtual model, so that the user can transform him/herself from a passive receiver into a genuine participant [21], [22]. The interactive aspect provides a real-time response and feedback model by modifying and configuring the parameters, allowing the design cycle to be shortened in the same way that manpower, and financial resources, required for repeated modification of the traditional design, can also be reduced. This imaginative feature signifies that the contents, which cannot be usually recognized, or experienced in the real world due to immature technology, or high costs, can now be realistically imagined via the use of virtual reality technology.

Thus, this research explores the idea of using virtual reality media for illustrating the content information in the form of a three-dimensional model. Studying towards the media which could be virtually sensed by the users can widen the users' vision and viewpoint of learning. This enhances the attractiveness of the content, in this case, electrical circuits, since the users can virtually and realistically experience the electronic laboratories safely. The users can study at their own pace whenever and wherever they go. Moreover, it can help the users or instructors save on costs as some electronic devices cannot be reused for learning purposes. When the virtual reality is combined with STEM-based learning, in which the scientific learning tools and engineering and mathematics technologies are applied, users are motivated to actively and quickly learn about electrical circuitry via virtual reality media. They are more likely to enjoy the learning process as this is a new and modern learning technology which is extraordinarily different from other learning tools like textbooks, or other forms of two-dimensional media. 


\section{$2 \quad$ Methodology}

The research methods for studying the development of the perspective electrical circuit simulation with virtual reality tool to teach electrical circuit, include the following steps:

\subsection{The Circuit to Be Simulated through Virtual Reality}

The electronic circuit to be simulated in this study is equipment required for electrical circuit installation such as a project board, multimeter, DC power supply, and resistor. Then, take note of the information about the direct current electrical circuit installation in various forms such as a simple circuit, series electrical circuit, two-loop circuit, three-loop circuit, and compound circuit. The value configuration for each electrical circuit installation is set as shown below:

- E refers to Voltage

- R refers to External Resistance

- $r$ refers to Internal Resistance

- I refers Electric Current

According to Kirchhoff's current law, Kirchhoff's voltage law, and Mesh current method, these values are used for calculating the formulae.

Series resistor installation

$\sum R=R_{1}+R_{2}+R_{3}+\cdots+R_{n}$

$\sum r=r_{1}+r_{2}+r_{3}+\cdots+r_{n}$

Parallel connected resistor installation

$\sum \mathrm{R}=\frac{1}{\frac{1}{\mathrm{R}_{1}}+\frac{1}{\mathrm{R}_{2}}+\frac{1}{\mathrm{R}_{3}}+\ldots+\frac{1}{\mathrm{R}_{\mathrm{n}}}}$

$\sum r=\frac{1}{\frac{1}{r_{1}}+\frac{1}{r_{2}}+\frac{1}{r_{3}}+\cdots+\frac{1}{r_{n}}}$

The voltage and electric current calculation.

$\sum E=E_{1}+E_{2}+E_{3}+\cdots+E_{n}$

$I=\frac{\sum E}{\sum R+\sum r}$

$\sum I_{\text {in }}=\sum I_{\text {out }}$ 


\subsection{Designing the perspective electronics circuit simulation with virtual Reality}

The design of the perspective electrical circuit simulation with virtual reality tool to teach electrical circuit for learning STEM electrical circuit activities is determined by the equipment and the direct current electrical circuit installation. Users can operate the virtual reality by looking through the camera headgear. The cardboard is made from hard paper with a hole to install a smartphone as illustrated in Figure 1.

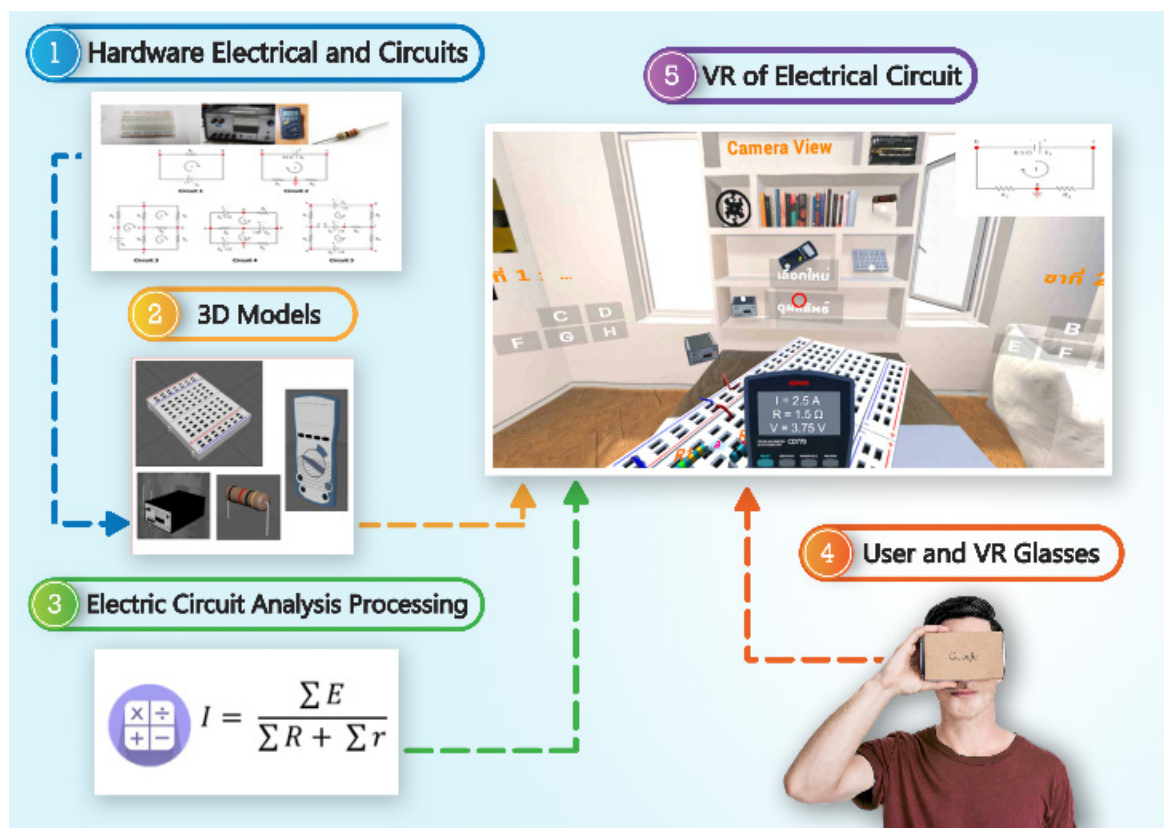

Fig. 1. The model of electrical circuits simulation with virtual reality.

\subsection{Development the electronics circuit simulation of virtual reality}

Based on the design process there was a construction of the 3D of electrical equipment and environment was development by MAYA. MAYA is a powerful program developed by Alias Systems Corporation [5]. The 3D model's development comprises of the equipment for electrical circuit installation as shown in Figure 2, and a private room environment designed for the learner's comfort as if they are playing with the electrical circuit at home, as is shown in Figure 3. 


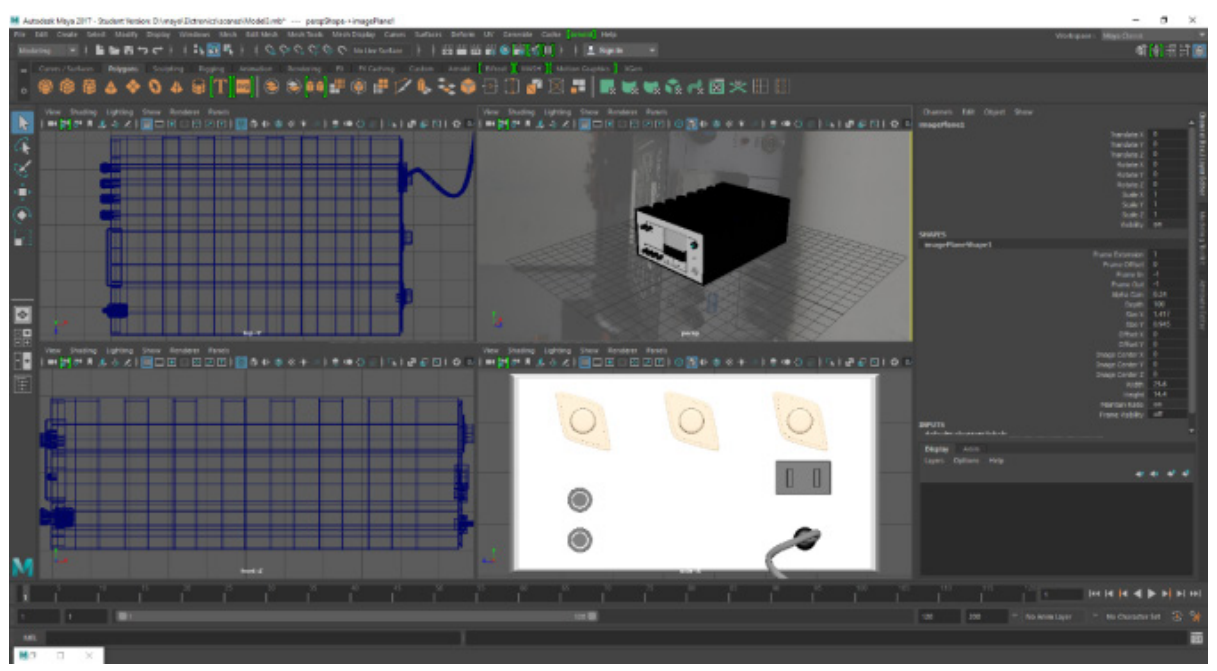

Fig. 2. The development of $3 \mathrm{D}$ voltage regulator.

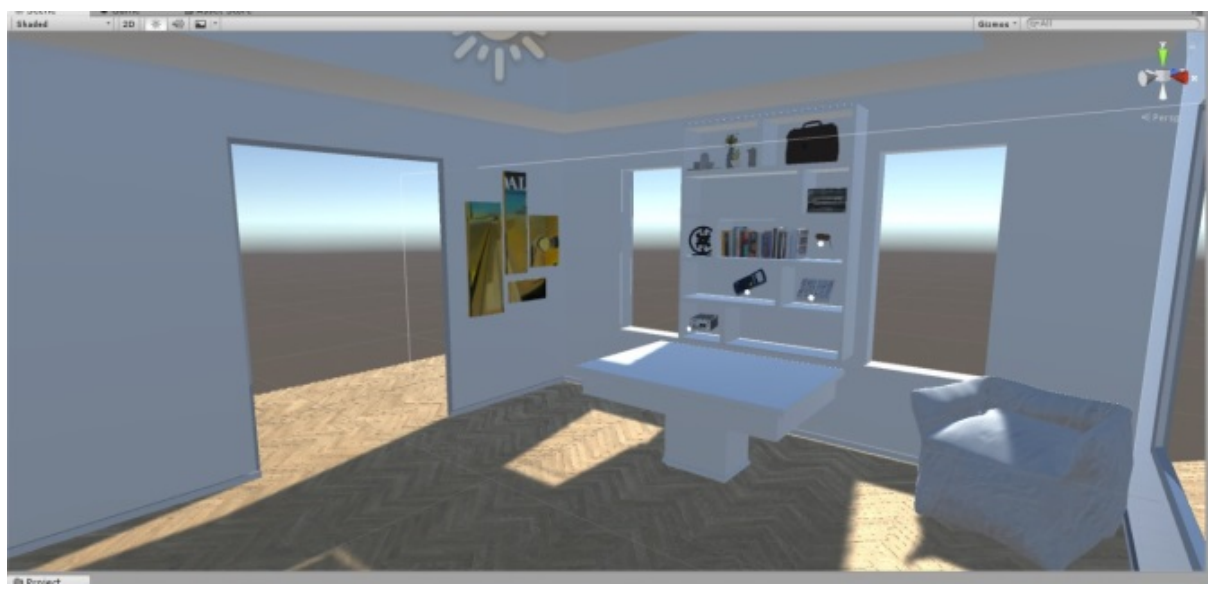

Fig. 3. The development of the 3D of the room environment for electrical circuit installation.

The development of virtual reality management requires computer programming of electric circuit analysis processing and the user's communication control panel for control of the virtual reality operation. After designing the three-dimensional model, the developers create the program to control the operations on the selection of the electrical circuit installation equipment, by visually examining the equipment, configuring the values, and validating the electrical circuit installation process. The duration of visual examination is two seconds. With respect to the three-dimensional model's development, there are the establishment of controls (buttons and tabs) on the control panel, the selection validation, and the electrical circuit installation validation on Android application was developed on Unity3D. Unity3D is a powerful game engine 
developed by the Unity Technologies Company [6]. Scripts of the application we have developed for this study are in the C\# software language, as shown in Figure 4.

The users can operate the virtual reality media, for learning electrical circuit activities, by studying the electrical circuit installation with the use of the VR glasses as described previously. The scene shown in front of the user's eyes is as illustrated in Figure 5.

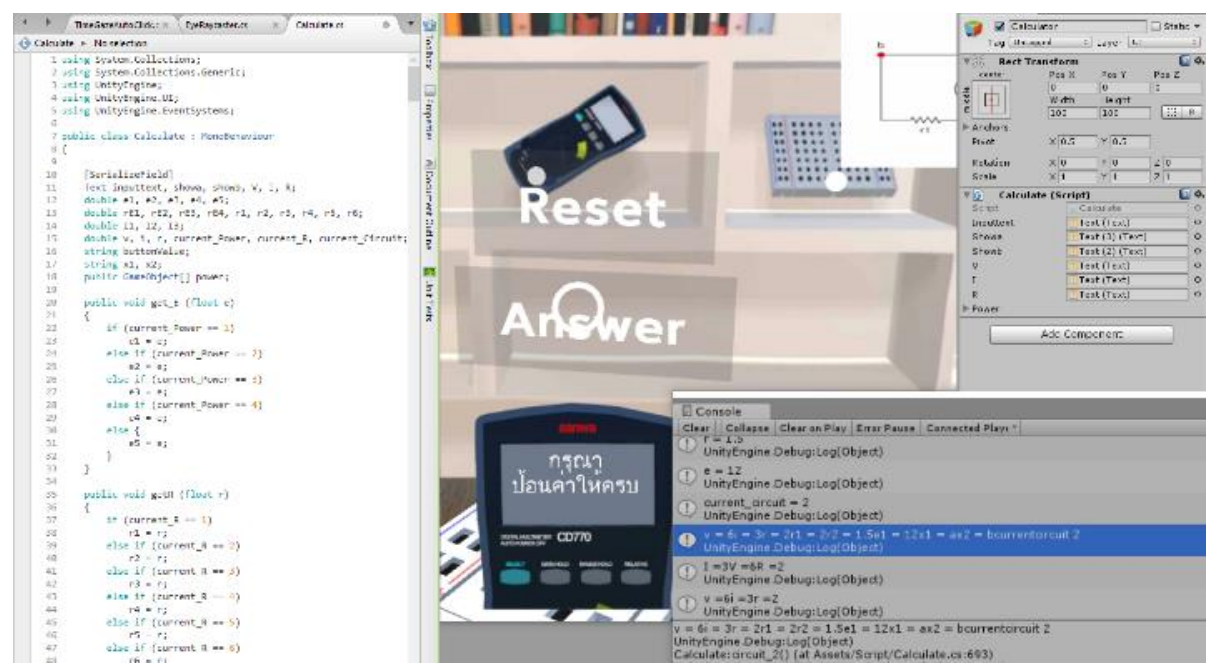

Fig. 4. C\# programming for the communication control panel.

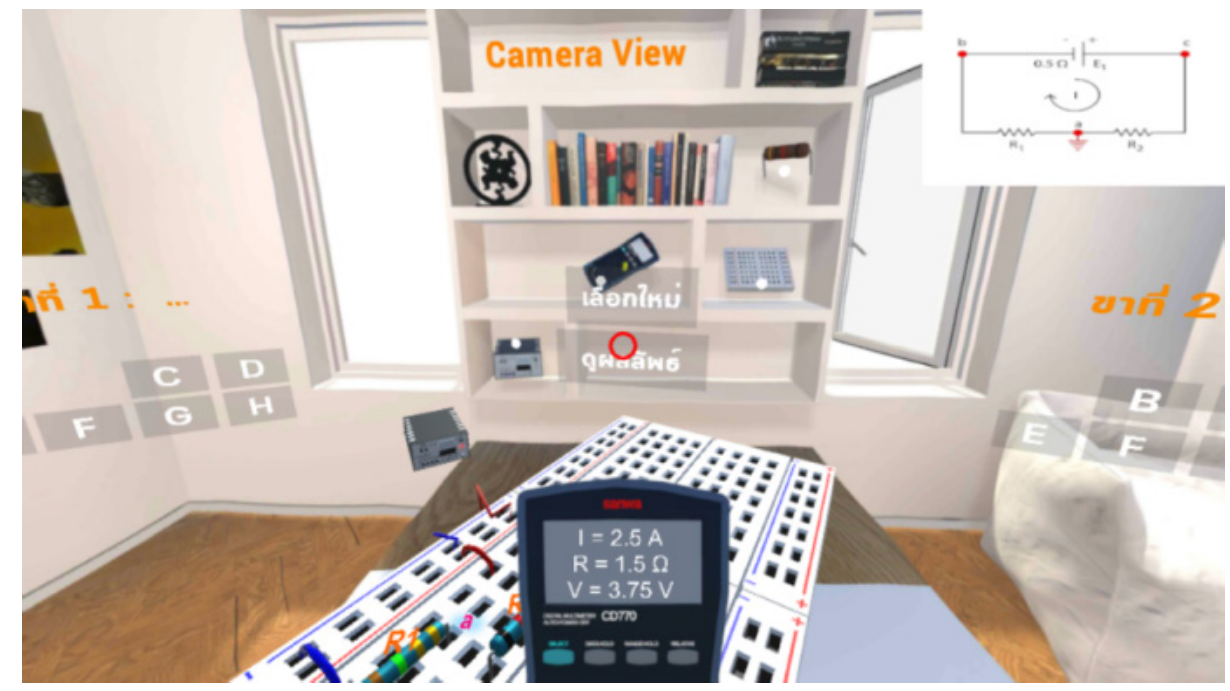

Fig. 5. Display of the simulation virtual reality for learning STEM electrical circuit activities on user's eye view. 


\section{Results}

The results of evaluation the electrical circuit simulation with virtual reality are as follows.

The virtual reality content, for learning STEM electrical circuit activities, the results of which are based on the Index of Item-Objective Congruence (IOC) [5], [7], [18] shows that after developing the virtual reality and assessing its congruence by five experts, the media was rated with 0.8 or higher for each criterion. The virtual reality was effective in accordance with the IOC value and usable for electrical circuit instruction.

- The evaluation results based on the Diffusion of Innovation Theory [8], [9], [10] assessed by the experts are categorized into five aspects.

- The innovation has greater benefits or advantages; with a mean of 4.20 and a standard deviation of 0.45 , it was demonstrated that the innovation was more beneficial or more advantageous at a high level.

- The innovation's convenience was rated with a mean of 4.00 and a standard deviation of 0 ; indicating that the innovation's convenience was easy-to-use at a high level. The innovation's visibility rated with a mean of 4.20 and a standard deviation at 0.45 ; demonstrating a high level of visibility.

- The innovation's compliance to demand, and the experience of the competent learners, in terms of innovation acceptance, had a mean of 4.60 and a standard deviation of 0.55 ; illustrating that the innovation complied with the demand and/or the experience of the competent learners in regard to the diffusion of innovation at a high level.

- The innovation's readily presented performance had a mean of 4.60 and a standard deviation of 0.55 ; indicating a performance that was readily presented at a high level. Overall, innovative effectiveness diffusion was rated with a mean valued at 4.32 and a standard deviation of 0.48 . In other words, the developed virtual reality for learning STEM electrical circuit activities was highly accepted with respect to innovative diffusion at a high level.

The evaluation of the effectiveness of virtual reality for learning STEM electrical circuit activities with respect to Diffusion of Innovation Theory are shown in Figure 6.

Evaluation of the virtual reality as assessed by 30 elementary school students was categorized into 4 criteria: 1) VR Feature; Immersion [11], Representational Fidelity [12], [13], and Immediacy of Control [12], [13]; 2) Usability; Perceived Usefulness [13], [14] and Perceived Ease of Use [8], [14] 3) Learning Experience; Learning Experience Presence [13], Motivation [15], and Cognitive Benefits [16] and 4) VR model Measurement Outcomes; VR Outcomes with the Intention to use the system [11], Perceived Learning Effectiveness [13] and Satisfaction [17]. 


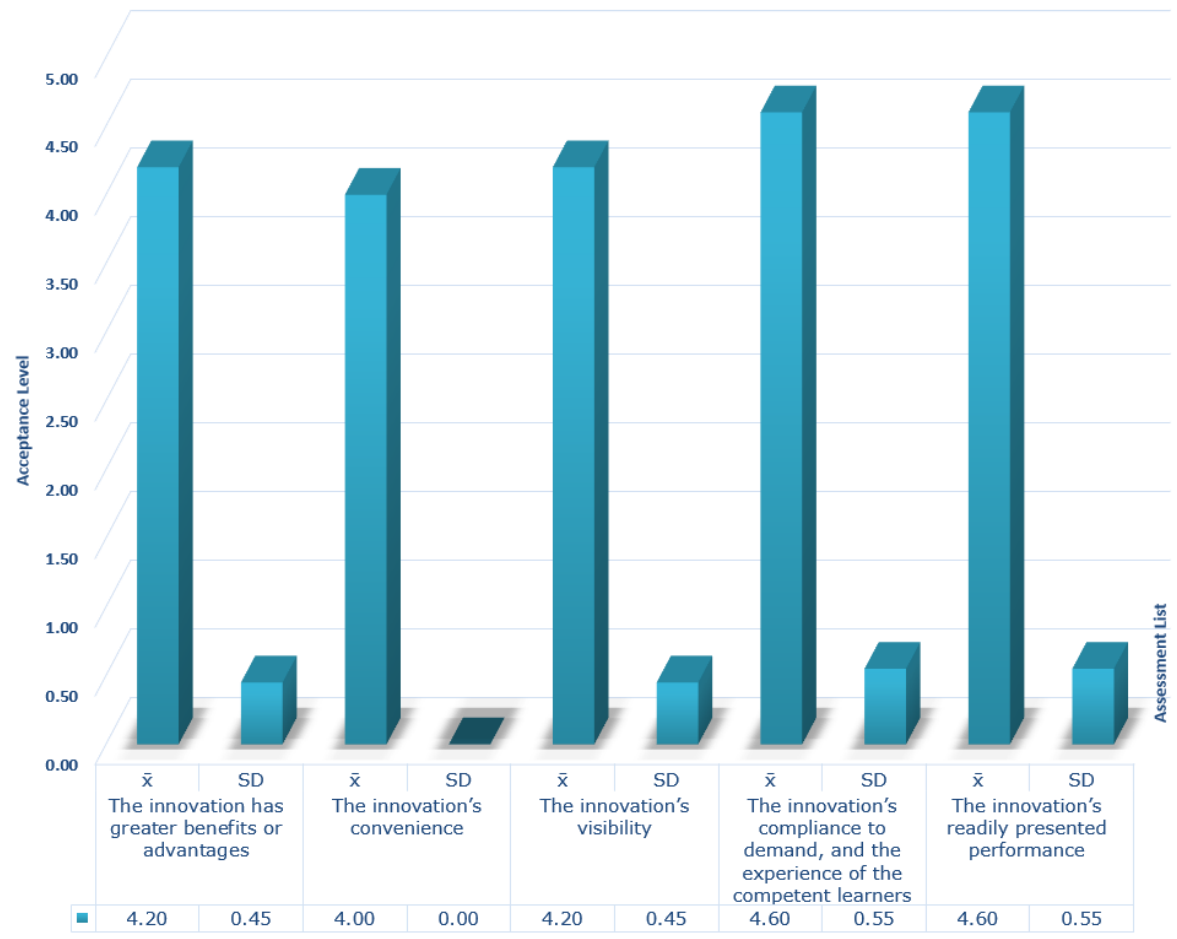

Fig. 6. Evaluation of the effectiveness of the virtual reality for learning STEM electrical circuit activities.

The evaluation of the virtual reality by the sample indicated that: 1) the VR Feature was rated with a mean of 4.64 and a standard deviation of $0.48 ; 2$ ) usability was rated with a mean of 4.60 and a standard deviation of 0.49 ; 3) the users' learning experience was rated with a mean of 4.68 and standard deviation of 0.47 ; and 4) the virtual measurement outcomes were rated with a mean of 4.72 and a standard deviation of 0.45 . In summary, the virtual reality as evaluated by the sample subjects in relation to the four criteria indicate effectiveness with a mean of 4.67 and a standard deviation of 0.47 . Strictly speaking, the virtual reality was determined to be the highest effective media for studying electrical circuits.

\section{Conclusion}

This paper presents the development of the virtual reality simulation media for learning STEM electrical circuit activities consisted of the learning of series electrical circuit installations to enable the design and development of appropriate virtual reality media. The virtual reality media was evaluated by five experts, determining that the Index of Item-Objective Congruence (IOC) and the Diffusion of Innovation Theory (DOI) was 0.8 for each content, while the DOI results had a mean of 4.32 and a standard deviation of 0.48 . This indicates that the virtual reality media developed for this 
study was suitable for the diffusion of innovation at a high level. Additionally, the virtual reality media was evaluated for Feature, Usability, Learning Experience, and VR Measurement outcomes, with a mean of 4.67 and a standard deviation of 0.47 , suggesting that the developed virtual reality media was the highest effective media in terms of electrical circuit learning. Additionally, after evaluating the virtual reality media's effectiveness with regard to information technology acceptance, it was determined that its mean was 4.64 with a standard deviation of 0.48 ; indicating subject acceptance of the technology at the highest level. That is, the virtual reality media for learning STEM electrical circuit activities can enhance the learning process of users at the highest level. By using this virtual reality media, students are able to apply the knowledge gained in constructing and fixing electrical circuitry. It is anticipated that this application will benefit instructors and students.

\section{Acknowledgement}

I would like to express our gratitude to the Office of the Higher Education Commission for funding this research study and also Institute for Research and Development, Suan Sunandha Rajabhat University, who offered us the opportunities to conduct this research

\section{References}

[1] Chittaro, L. and Ranon, R. (2018). Web3D technologies in learning, education and training: Motivations. Computers \& Education. 49 (1), 3-18. https://doi.org/10.1016/j.compedu.2005.06.002

[2] Pan, Z., Xu W., et al. (2003). EasyBowling: a small bowling machine based on virtual simulation. Computers \& Graphics. 7(2), 231-238. https://doi.org/10.1016/S00978493(02)00280-7

[3] Blackledge, J. and Barrett, M. (2012). Evaluation of a Prototype Desktop Virtual Reality Model Developed to Enhance Electrical Safety and Design in the Built Environment." ISAST Trans. on Computing and Intelligent Systems. 3(3), $1-10$.

[4] Richard, C. D. and James, A. S. (2010). Introduction to Electric Circuits. John Wiley \& Sons, US.

[5] Nuanmeesri, S. (2018). The Augmented Reality for Teaching Thai Students about the Human Heart. International Journal: Emerging Technologies in Learning. 13(6), 203-213. https://doi.org/10.3991/ijet.v13i06.8506

[6] Özüağ, M., Cantürk, İ. and ÖzyilmazS, L. (2018). A New Perspective to Electrical Circuit Simulation with Augmented Reality. International Journal of Electrical and Electronic Engineering \& Telecommunications. 8(1), 1-5.

[7] Turner, R. C and Carlson, L. (2012). Index of Item-Objective Congruence for Multiple Objective Measures. Unpublished manuscript, University of Arkansas.

[8] Roger, E. (1995). Diffusion of Innovations. Free Press. New York.

[9] Agarwal, R. and Prasad, J. (1997). The role of innovation characteristics and perceived voluntariness in the acceptance of information technologies. Decision Science. 28(3), 557582. https://doi.org/10.1111/j.1540-5915.1997.tb01322.x 
[10] Chaveesuk, S., Jaturapa, S. (2010). Theory of acceptance and use of technology. KMITL

[11] Information Technology Journal, 1(1), 1-21.

[12] Huang, H. M., Rauch, U. and Liaw, S. S. (2010). Investigating learners' attitudes toward virtual realigy learning environments: Based on a constructivist approach. Computers \& Education. 55, 1171-1182. https://doi.org/10.1016/j.compedu.2010.05.014

[13] Dalgarno, B., Hedberg, J. and Harper, B. (2002). The contribution of 3D environments to conceptual understanding. Proc. of ASCILITE, New Zealand.

[14] Lee, E. A., Wong, K. W. and Fung, C. C. (2010). How does desktop virtual reality enhance learning outcomes? A structural equation modeling approach. Computers \& Education, 55, 1424-1442. https://doi.org/10.1016/j.compedu.2010.06.006

[15] Davis, F. D. (1989). Perceived Usefulness, Perceived Ease of Use, and User Acceptance of Information Technology. MIS Quarterly. 13, 319-340. https://doi.org/10.2307/249008

[16] McAuley, E., Duncan, T. and Tammen, V. V. (1989). Psychometric properties of the Intrinsic Motivation Inventory in a competitive sport setting: a confirmatory factor analysis. Research Quarterly for Exercise and Sport. 60, 48-58. https://doi.org/10.1080/02701367.1989.10607413

[17] Antonietti, A., Imperio, E., Rasi, C. and Sacco, M. (2001). Virtual reality and hypermedia in learning to use a turning lath. Journal of Computer Assisted Learning. 17, 142-155. https://doi.org/10.1046/j.0266-4909.2001.00167.x

[18] Chou, S. W. and Liu, C. H. (2005). Learning effectiveness in a web-based virtual learning environment: A learner control perspective. Journal of Computer Assisted Learning. 21, 65-76. https://doi.org/10.1111/j.1365-2729.2005.00114.x

[19] Sumitra, N., Preedawon, K. and Lap, P. (2016). Publicizing Thai Dress of Royal Endorsement by Augmented Reality. The Social Sciences Journals. 11(14), 3563-3568.

[20] Fernando, C., Rafael, T., José R., Paulo A., and Maria, T. R. (2018). A Gamified Approach for Hand Rehabilitation Device. International Journal of Online Engineering. 14(1), 179-181. https://doi.org/10.3991/ijoe.v14i01.7793

[21] Tom, A. E., Ivana, M. and Kamau, W. (2017). Applications and App Building in Hybrid Courses. International Journal of Online Engineering. 13(1), 65-76.

[22] Mark, S., Ananda, M., Andrew, D. M. and Alexander, A., K. (2016). Augmented and Mixed Reality Features and Tools for Remote Laboratory Experiments. International Journal of Online Engineering. 12(7), 45-52. https://doi.org/10.3991/ijoe.v12i07.5851

[23] Shanhui, Z., Chaoying, Y. and Ning, X. (2016). A Guiding Design System for Pressure Vessels based on 3D CAD. International Journal of Online Engineering. 12(5), 4-8. https://doi.org/10.3991/ijoe.v12i05.5721

\section{$7 \quad$ Author}

Sumitra Nuanmeesri renders services at the University of Suan Sunandha Rajabhat.

Lap Poomhiran works at the Suan Sunandha Rajabhat University, Bangkok 10130 Thailand.

Article submitted 2018-10-05. Resubmitted 2018-11-17. Final acceptance 2018-11-17. Final version published as submitted by the authors. 